\title{
MITO Y HERMENÉUTICA \\ EN LAS COMEDIAS PALACIEGAS DE CALDERÓN
}

\author{
Enrica Cancelliere \\ Dipartimento di Studi Umanistici \\ Facoltà di Lettere e Filosofia \\ Università degli Studi di Palermo \\ Viale delle Scienze, Edificio 12 \\ 90128 Palermo. Italia \\ enricacancelliere@libero.it
}

[Anuario calderoniano (ISSN: 1888-8046), 7, 2014, pp. 99-128]

Esta trabajo pretende definir una «fábula» según la reelaboración mitológica de Calderón, hecha de estereotipos detectables con particular constancia en el repertorio mitológico del poeta: una especie de esquema supeditado a todas las variantes de los mitos en cuestión, y por lo tanto un mapa soportado por un personal planteamiento hermenéutico, coincidente con una poética de autor.

A través de un reconocimiento del corpus completo de las comedias mitológicas calderonianas ${ }^{1}$, hemos enucleado los «mitologemas» recurrentes. Por $«$ mitologemas» ${ }^{2}$ se entienden en la semiótica textual

\footnotetext{
${ }^{1}$ Ver Chapman, 1954. Se citan las comedias y los dramas de Calderón por la edición de Valbuena Briones, 1966.

${ }^{2}$ Ver Kristeva, 1978, pp. 97-118.
} 
los topoi mitológicos —estereotipos de acción, situación, objetos, lugares, actantes- que se repiten con insistencia taxonómica en una gran cantidad de mitos y leyendas de una determinada tradición cultural, o incluso de varias tradiciones culturales, como podría ser el caso de mitologemas repetidos entre la tradición griego-helenística y la sánscrito-hindú. Tales topoi desempeñan funciones simbólicas prácticamente constantes y, por tanto, atribuyen a las «fábulas» en las que se insertan sus connotaciones de significado, las cuales a su vez con total probabilidad remiten a significados esotéricos de liturgias y dinámicas codificadas en arcaicos ritos tribales de iniciación o propiciatorios ${ }^{3}$.

El hecho de que un autor acoja mitologemas en su corpus textual podría representar solamente un caso de erudición o de cuidado filológico, pero no cuando - como acontece precisamente en Calderón- se privilegian algunos con reiterada frecuencia adaptándolos a los más diversos desarrollos de las varias "fábulas» tratadas, y sobre todo con sustancial constancia de las funciones simbólicas. En este caso tenemos que reconocer que los mitologemas seleccionados y recurrentes entran a formar parte de una Weltanschaunng de autor que se manifiesta a través de ellos simbólicamente como connotación de los textos.

En el corpus mitológico calderoniano hemos notado la presencia constante de siete mitologemas; se trata, quede bien claro, de un esquema arbitrario que no excluye otros posibles, pero que parece adecuado y exhaustivo en cuanto a las funciones de modelización de los topoi mitológicos que se encuentran en esos textos.

Cada uno de los mitologemas desempeña una función simbólica constante en su generalidad, y a la vez compleja, como si se tratara de un haz unitario de diferentes simbolizaciones posibles, aun distantes las unas de las otras pero atribuibles a un mismo principio. Las variantes dependen de las funciones diegéticas y de las definiciones descriptivas que va aportando el autor según los diferentes contextos.

Hemos definido estas variantes de cada mitologema como «motivos», según Propp. El reconocimiento nos ha llevado a establecer, para cada uno de los siete mitologemas, cuatro diferentes motivos que componen el haz de funciones simbólicas posibles.

${ }^{3}$ Ver Propp, 2000. 
El número cuatro — recuérdese la cuatripartición semiótica de Greimas ${ }^{4}$, la cuatripartición ritual y antropológica de Lévi-Straussse connota por un valor evocativo por el hecho de que el cuarto término funciona como elemento conmutador, sede del «mana», y en este sentido simboliza el mundo en todas sus formas de lenguaje, desde los antiguos chamanes hasta los poetas.

Referimos por consiguiente esta modelización, resultante del excursus sobre el corpus textual a base de ejemplos.

Analizaremos, pues, el esquema siguiendo una sucesión lógica, que es la que generalmente pone en secuencia en cada «fábula» los mitologemas como motores del desarrollo diegético.

Sin embargo hace falta subrayar que al analizar los mitologemas, y no solo por la dislocación de algunos de ellos en el plot con respecto al esquema-fábula, sino sobre todo por su entrelazarse, dialectizarse, contaminarse y connotarse recíprocamente, estos van adquiriendo un valor de polisemia simbólica verdaderamente compleja. Aun es preciso advertir que la modelización que proponemos atañe a los conocidos "seis teatros barrocos», en que se articula el plot y la puesta en escena codificados en el mismo corpus, solo por casuales puntos de contacto. Por ejemplo, es obvio que el mitologema del «lugar salvaje y encantado» se representa casi siempre en el «teatro de bosque», o «de monte», pero no de forma exclusiva: hay fábulas en que ese mismo mitologema se desarrolla en un «teatro de mar», hasta «de palacio».

Abre la lista de los siete mitologemas el del "cataclismo», un evento o accidente que determina desorden y conflicto. Cuatro son los motivos a través de los cuales puede manifestarse concretamente en la escena en cada comedia, sin excluir que aquí, como en otros lugares, varios motivos puedan manifestarse juntos o coexistir. Estos cuatro motivos son: la furia y la lucha de los cuatro elementos cosmogónicos y el consiguiente eclipse, más que solar, de la entera luz del Cosmos precipitado en el Caos; la caída (del héroe, del caballo, o de lo que sea) y el precipitarse en el abismo; la guerra destructora y promotora de odio e irracionalidad; el furor violento y/o vengativo (de un dios, de un monstruo, del héroe).

Está claro que aquí el último término puede poner en correlación y conmutar los demás motivos; el procedimiento, es obvio, se repite

${ }^{4}$ Greimas, 1969, 1974. 
con respecto a los motivos de los otros seis mitologemas que analizaremos.

La función simbólica de todo este mitologema, que definimos como "cataclismo", remite al significado del Caos, bien sea de la naturaleza, de la historia, del alma, o de todas estas cosas aunadas (recuérdese ese ejemplo paradigmático que es La hija del aire).

El naufragio con el que comienza El mayor encanto, Amor es la consecuencia del estallido de los cuatro elementos. El mar, el viento, los relámpagos y la escollera, son de hecho las causas de un desastre que se manifiesta en el caos de la naturaleza, pero que metaforiza el caos del alma y del entendimiento. Es obligado citar los antecedentes de la obra: la comedia mitológica Polifemo y Circe escrita por el mismo Calderón en colaboración con Mira de Amescua y Pérez de Montalbán; y, aún más interesante, una trama de la Commedia dell'Arte, La Arcadia incantata, de autor anónimo. Sin embargo, el tema de la tempestad y del naufragio, con análogos entendimientos simbólicos, se encontraba ya en apertura de algunos dramas shakesperianos: La tempestad, Cuento de invierno, Noche de Reyes, y se encuentra con frecuencia en las óperas de la Camerata dei Bardi. Así pues se trata de un motivo estereotipado en la dramaturgia y en las óperas líricas barrocas, que nuestro autor acoge en más de una ocasión; recordemos, entre los muchos ejemplos el comienzo de La fiera, el rayo y la piedra que anuncia el mitologema ya a partir de la acotación: Obscurécese el teatro, que será de peñascos, con el foro de marina, y mientras se dicen los primeros versos, se descubre la perspectiva del mar y habrá truenos y relámpagos. De forma diferente, por la manera de emplearlo en el plot, el motivo del caos de los cuatro elementos y el consiguiente eclipse del sol, puede introducir nacimientos anormales y/o acontecimientos monstruosos. Un ejemplo, que podemos considerar paradigmático, es el nacimiento de Segismundo, del cual nos da noticia el mismo rey Basilio.

En su valor alegórico sus palabras se pueden interpretar según el patrón doctrinal del Viejo Testamento que considera el nacimiento de todo ser humano como la reiteración de la culpa del pecado original, a la espera de una redención de toda la Humanidad. Pero las mismas palabras se prestan a una interpretación avalada por las actuales epistemologías ofrecidas por la antropología, a partir del tema de la sucesión real en La rama dorada de Frazer, del psicoanálisis a partir de Tótem 
$y$ tabú de Freud, y del trauma del nacimiento de Otto Rank ${ }^{5}$. De todas formas la sucesión de generaciones genera y atraviesa el Caos, para culminar con la recomposición del Cosmos en la renovada «basilización» que confirma la continuidad y reitera la identidad entre padre e hijo.

A propósito de El mayor encanto, Amor la acción comienza con una tormenta de mar:

Antisteo

ARquelao

TIMANTES
En vano forcejamos

cuando rendidos a la suerte estamos, contra los elementos.

Homicidas los mares y los vientos

hoy serán nuestra ruina.

$[\ldots]$

Causando está desmayos

el cielo con relámpagos y rayos

$[\ldots]$

Monumentos de hielos

hoy serán estas ondas.

(p. 1510)

Luego la embarcación de Ulises se deshace contra las costas de la Trinacria, y, a partir de ese momento comienza el recorrido del héroe y de sus compañeros en un isla de encantamientos y de metamorfosis donde, a causa de los hechiceros de la maga Circe, el héroe, perdido su raciocinio, acabará con extraviarse. Otra catastrófica tormenta de mar, con la implicación una vez más de los cuatro elementos, es la que produce con sus artes mágicas Circe para vengarse de Ulises:

Circe

$[\ldots]$

Llamas las ondas arrojen, fuego las aguas espiren.

Sale fuego de las aguas.

Arda el azul pavimento

y sus campañas turquíes

mieses de rayos parezcan

${ }^{5}$ Frazer, 1983; Freud, 1989; Rank, 1990, 1994. 
que cañas de fuego vibren

a ver si hay deidad que tanta

tormenta le facilite.

(p. 1544)

En El golfo de las sirenas, la hechicera Escila airada provoca una tormenta de mar despejando rocas sobre la embarcación de Ulises en fuga:

Escila [Dentro] Llamadle, detenedle!

Que yo guerra también le haré de suerte...

\section{Terremoto}

Ella y SIRENAS $\quad$... que en calma sienta, llore, gima y pene, conociendo que el golfo

de las sirenas,

el que apenas le surca

le surca a penas.

(p. 1735)

El tema odiseico siempre es congenial con el del Caos y los cuatro elementos por los valores reales y metafóricos que desde Homero connotan las andanzas por mar del héroe, manifestación del errar de su espíritu inquieto.

En la Epistula LXXXVII, Séneca interpreta las peripecias y adversidades de Ulises como progresivo viaje interior a través de la tempestad de las pasiones que amenazan el entendimiento humano; mientras en su De vita Beata, el autor exalta el sentido de autoconciencia que libra al hombre de su naturaleza bestial y ferina. Pérez de Moya en su Filosofía secreta (1585) —una de las fuentes más usadas por Calderón - había hecho propio el estoicismo de Séneca, así como otros autores moralistas. Dante acoge esta interpretación estoica pero añadiendo un sentido de ansia de conocimiento y de temeraria osadía que llegarán hasta el moderno mito faustiano. Por otra parte ya en los mitos griegos se caracterizaban por análogos significados metafóricos: de Ulises a Ícaro, de Teseo a Prometeo, de Jasón a Faetón. Significados que hereda Calderón, a pesar del influjo senequiano, gracias a su racional escolasticismo mezclado a una visión neoplatonizante según un movimiento ascensional del espíritu: el héroe calderoniano está movido por el deseo de actuar según un procedimiento racional 
de su intelecto para conseguir los más altos triunfos que, por eso, llegan siempre a la apoteosis, y, por consiguiente, sus renuncias son siempre mortales.

El mismo Séneca en el De Providentia considera al soberbio Faetón un ejemplo de héroe que representa con firmeza su propio ineludible destino. Versión recogida por Calderón en El hijo del Sol, Faetón, donde se asiste a un preanuncio del tema de los elementos ya cuando Tetis asimila al aire la soberbia del héroe hasta su desencadenamiento simultáneo en el vuelo incendiario, que hace precipitar en el abismo del mar a Faetón, loco de amor y celos, conduciendo el carro del padre, el dios Apolo. La caída desastrosa del carro desde las alturas solares, el caos devastador de los cuatro elementos, el incendio, la furia de la pasión — vaticinada, además, por un oráculo- consienten al conjunto de los motivos activados la explosión del mitologema en su máxima entropía:

FAETÓN ¿Quién creerá que en tanto asombro yo abrase al mundo y a mí? Mas ¿qué mucho, si a mis ojos a Tetis, jay infelice!, llego a ver en brazos de otro? Y así, perdido lo más, ni rienda que airado arrojo, ni curso que ciego pierdo, podrán hacer que sea estorbo de no despeñarme al mar, y pues ardo yo, arda todo. $[\ldots]$

Batillo $\quad[\ldots]$ el cielo sobre nosotros se cae y no más.

ADMETO Y ERÍDANO Los ejes del cielo caducan todos. (p. 1902)

En fin, el mundo no está en sus ejes. El mitologema del «cataclismo» se hace cósmico porque todo el universo está arruinado en el Caos. Recordemos, por el valor paradigmático, el final de la Tercera Jornada de la Primera Parte de La hija del aire: 
SEMíramis

La fábrica de los cielos

sobre nosotros se hunde,

a cuyo estallido todos

los ejes del polo crujen.

(vv. 3312-3315)

El simulacro de Pandora, en La estatua de Prometeo, nace simbólicamente de los elementos puesto que la tradición dice que este simulacro es una pasta de tierra y agua, forjado por un soplo divino que se manifiesta en una llamarada. En Calderón la Discordia reconoce el origen del fuego (fuego apolíneo, pero también del antro alquímico, parecido al fuego del que se sirven los Cíclopes) del hermoso simulacro viviente, y por eso le ofrece una urna dorada que contiene los dones divinos, de la tierra y del agua con la significativa añadidura del Eco en lugar del fuego. A ello seguirá, como sabemos, el cataclismo, lo que a su vez no es sino un signo simbólico de la general discordia y de la violencia con la que los opuestos hermanos, Prometeo y Epimeteo, ensangrentan el mítico Cáucaso, caudillos de una guerra fratricida:

Cuando Pandora, animada por el deseo de repartir con todos los humanos en fiesta los magníficos dones de los dioses, destapa la urna, un estallido de humo y un terremoto oscurecen de repente la escena con un auténtico golpe teatral; quizás desde el punto de vista escenográfico y luminotécnico el más asombroso entre los muchos que jalonan la fiesta.[...] En efecto el mundo parece hundirse en el caos $^{6}$.

La metáfora del mundo es evidente, así como la esperanza del regreso de la Edad de Oro en la visión del carro de Apolo y luego de la Apoteosis final.

Uno de los componentes del mitologema del «lugar inaccesible y salvaje» es el motivo de la naturaleza agreste, desértica o montuosa, pero lo puede representar también una isla de peligrosos hechizos. Por lo general este motivo es preámbulo al sucesivo de la caverna, gruta, o antro que sea, cuya función es doble, porque puede simbolizar la perdición, la desaparición del sujeto, que se extravía lejos de la luz de

${ }^{6}$ Cancelliere, 2010, p. 83. 
la autoconsciencia, pero también lugar de prodigios, cavidad en la que se forjan las apariciones iniciáticas y/o las revelaciones de lo verdadero. Sigue el motivo de la «cárcel» (del cuerpo y/o del alma) que puede ser representada concretamente por la caverna misma, o una torre, o una verdadera prisión, e incluso un palacio principesco o un jardín más o menos laberíntico. Y en fin, el motivo de la «boca de los Infiernos», o del «umbral del Más Allá», de cualquier Más Allá ulterior a la existencia. El topos traduce, pues en su conjunto, el errar del héroe, su deslumbramiento, la lejanía del objeto de deseo, la ausencia de la luz de la conciencia; pero también lo dialécticamente exacto y contrario: el lugar de la revelación o de la posible aparición del prodigio, que lleva a la luz de lo verdadero, y de la autoconsciencia. El mitologema radica de hecho en la liturgia espacio-temporal del ritual de iniciación: aislamiento del héroe en un lugar-tabú ignoto infinitamente alejado en el tiempo y en el espacio, aunque realmente muy cerca de la aldea o del palacio; reclusión en una caverna o algo parecido por el trance y las torturas rituales (contraseñas de muerte) bajo los cuidados y la enseñanza de una «bestia sabia» (animal totémico); revelación del padre y pacificación-transmisión de los poderes; vuelta triunfal del iniciado a la aldea o al palacio porque ha pasado de la muerte a la vida reencarnando al padre y sus funciones reales. Ejemplo paradigmático es precisamente La vida es sueño ${ }^{7}$.

Encontramos este mitologema del «lugar inaccesible y salvaje», en su variante de lugar de prodigiosos hechizos también en El mayor encanto, Amor. La acción, como se ha dicho, se desarrolla en una isla de encantamientos, una Trinacria que recuerda la Sicilia de La tempestad shakesperiana - la isla de las utópicas Bermudas que se encuentra a lo largo de la ruta entre Nápoles y Cartago- y, por consiguiente, representa el lugar ideal en el cual puedan manifestarse los más extraordinarios prodigios y metamorfosis de que es artífice la maga Circe. El hecho de que los efectos escenográficos realizados por Cosimo Lotti se realicen en un islote en medio de un estanque, ambos construidos para la ocasión en el parque del Buen Retiro, constituye un reforzamiento del valor metafórico del poiein calderoniano y, al mismo tiempo, una alegoría que pone en relación la Corte y el mito. Por otra parte Asia recorrida por Jasón, Europa por Teseo, África por Hércules

${ }^{7}$ Cancelliere, 1979, pp. 45-60; 2000, pp. 273-331; Propp, 1975. 
- héroes de los tres continentes que van a la búsqueda de Deanira raptada por el Centauro- no son territorios reales sino los inmensos espacios inaccesibles de Los tres mayores prodigios, en que pueden generarse los mitos como fundamentos de la humanidad y de la civilización en los tiempos venideros. La función simbólica del espacio articula la Jornada II, en el momento en que toda la naturaleza - los bosques, el monte, el arroyo y el aire- se hace testigo de los lamentos de Ariadna abandonada con una evidente referencia al motivo de los «cuatro elementos» como otra fundamental representación del mitologema del Cosmos y del Caos.Y por lo que se refiere al topos del «Lamento de Ariadna» en las representaciones en música, desde Monteverdi hasta Strauss, el excursus sería muy largo, pero de este Calderón no solo hace parte sino que está en la encrucijada.

Volviendo al texto, la maldición que lanza la infeliz Ariadna, al presagiar los infaustos acaecimientos tras las bodas entre Teseo y Fedra, pone en relación aquel mito con el motivo de las Furias y de los dioses infernales, poniendo de relieve todas las valencias simbólicas del lugar desolado y/o salvaje en su connotación de umbral de la caverna tras el cual se abren las puertas del Infierno, o de la Nada, aun, del vacío y abismo existenciales.

Otra vez una Trinacria mítica es el espacio que acoge La fiera, el rayo y la piedra. Sin embargo en esta pieza prevalece el «teatro de bosque», lugar donde se pierden, en la supuesta realidad dramática (y en la metáfora del extravío del Sujeto) los tres protagonistas Céfiro, Pigmalión e Ifis, y donde se producirán las visiones monstruosas y portentosas. Sin embargo este extravío en el bosque lo ha causado un cataclismo que vuelve a connotar la metáfora del Caos a través del motivo de los cuatro elementos. Los tres héroes, atormentados por los acontecimientos, se mueven en un espacio, físico y mental, inaccesible, hecho de precipicios, despeñaderos y barrancos que conectan hondos abismos con la selva y el bosque. A partir de aquí los tres protagonistas intentan su difícil recorrido ascensional -incluso desde el punto de vista escenográfico - hacia los Cielos. La diegesis, pues, se va desarrollando a través de la articulación de los cambios de escena y de la scaena ductilis —en esta ocasión realizada por Luigi Vaggiocon maravillosos efectos de la función escópica, a través de un recorrido ascensional de salvación y conocimiento hasta la apoteosis final. 
En Apolo y Climene, en un inaccesible monte, connotación de un lugar-tabú, por el hecho de que por decreto del rey Admeto está condenado a muerte quienquiera intente profanarlo, se encuentra el templo-prisión de la infeliz Climene. Esta, pues, se queja de su condición de sepultada viva con palabras que recuerdan las de Segismundo: animado-muerto; vivo-cadáver, etc. Y es el motivo de la gruta - representada escenográficamente al comienzo de la obra- el que determina el destino de su infelicidad, como sabe la misma Climene: «la mortal tristeza / de haber nacido a vivir / sin vivir, pues mi primera cuna y último sepulcro / su centro fue» (p. 1817). Otra vez el mitologema del «lugar inaccesible» anuncia la representación del motivo del palacio-prisión del monstruo prodigioso que vive su abisal profundidad. Aquí una fuerza divina infringe el tabú: la llegada de un peregrino que es, en fin, el gran dios Apolo.

Semejantes quejas difundirá por el aire Narciso en Eco y Narciso. Reducido a la condición de un salvaje o una fiera humana, desde la profundidad de una gruta que se abre dentro de una tupida selva inaccesible, a causa de las atenciones, excesivas y tiránicas, de la madre Liríope.

Luego el mismo Narciso va a refugiarse en un monte abrupto y escarpado para huir de Eco, aunque la desee desesperadamente, porque su madre Liríope le convence del influjo nefasto que ejerce sobre él. Alrededor de este monte una armoniosa Arcadia, con sus vegas amenas, verdes huertas, sonoras fuentes y ricos rebaños, es el lugar simbólico de la "u-topía», donde dialécticamente puede encerrarse el núcleo obscuro de la selva, cárcel de aquel portento humano, Narciso, prisionero al mismo tiempo de su madre y de su mismo fantasma.

El motivo de la naturaleza árida y desértica es especular al de la isla, cuando Cupido es obligado a abandonar a su Siquis en Ni Amor se libra de Amor. Aquí la sustitución del motivo, que ya fue de Apuleyo, del monte inaccesible con el de una isla desierta, determina una entropía espacial del mitologema, porque en este espacio pueden evocarse todas las posibles magias y acaecimientos prodigiosos relacionados con el motivo de la isla. Esta, a su vez, evoca el elemento del agua prefigurando un Cosmos, especular entre mar y cielo, como espacio que puede acoger a Siquis, abandonada por Cupido, y a sus tristes quejas, según el conocido topos de "Ariadna abandonada». A causa de esta desazonada desesperación, su imagen llega a fijarse en el icono de 
la infelicidad que es propia de la belleza destinada desde siempre a la violencia y al abandono:

SiQuis

Mas un padre y un amante,

y que entrambos la aborrezcan, no solo la historia, pero

la fábula aun no lo acuerda.

¡Ay, infeliz de aquella que a estrenar ejemplares nació expuesta!

El topos vuelve a manifestarse en las quejas de Doris, en Fineza contra fineza, cuando la joven sacerdotisa llega al lugar donde de costumbre se encontraba a escondidas con su amado Celauro, que ahora cree muerto. Otra vez una naturaleza salvaje e inculta (estéril) se ofrece como escenario del melancólico llanto y de la música:

DORIS

$$
\begin{aligned}
& \text { Si estas sombras, si estas ramas, } \\
& \text { este horror, este silencio, } \\
& \text { estas fuentes y estos cuadros } \\
& \text { callados testigos fueron } \\
& \text { de mis gozos, ¿por qué no lo han } \\
& \text { de ser de mis tormentos? } \\
& \text { (p. 2112) }
\end{aligned}
$$

En El monstruo de los jardines, dentro de una naturaleza intrincada y abrupta se encuentra una inaccesible gruta que es el refugio donde se ampara Aquiles, protegido por su madre maniobrera e intrigante, hasta el momento en que decide ir a Palacio para abrazar a su amada Deidamia.

El motivo de la naturaleza inasequible y salvaje es el marco en que se representa el mito de Prometeo y de su Pandora en La estatua de Prometeo, a partir de la Jornada Primera que se abre con un «teatro de monte", según acotación: Ábrese un peñasco y sale Prometeo. Al salir el héroe empieza a llamar a voces a todos los habitadores de aquellos profundos valles y de las altas cumbres de un Cáucaso imaginario y fantástico, localización mítica de la cuna de la Humanidad en las mitologías y en el Viejo Testamento. Y puesto que los invita a ver y admirar un prodigio portentoso que está dentro de su gruta, que es el 
lugar esotérico de sus estudios y de sus artificios, el motivo en su complejidad nos lleva a la memoria otros muy conocidos y fundantes de la poética calderoniana: la gruta de Semíramis; la torre-caverna de Segismundo, lugares donde viven encarcelados desde su nacimiento, etc. Pero aquí el prodigio no es una fiera humana sino más bien un simulacro.

Por consiguiente podemos afirmar que el «motivo del antro» se conecta de forma estable con el del «lugar inaccesible o encantado» y prodigioso, también cuando se presenta según tipologías distintas, como por ejemplo el templo donde vive encerrada Climene. Y por lo que se refiere a la Cueva de las Parcas, en La fiera, el rayo y la piedra, Parcas que no por casualidad vaticinan el nacimiento de un "monstruo» que es la causa del cataclismo y de la eclipsis del comienzo determinados por los cuatro elementos, se vuelve a evocar, de hecho, aquella connotación del Más Allá, de las sombras, de una vida novida, que hemos demostrado ser una de las connotaciones propias del «motivo de la cueva».

Interesante en esta comedia palaciega es la función de la deixis del espacio que se articula según una tripartición en abismo: el Alcázar, palacio real-prisión de Anajarte que, fiera cazadora destinada a congelarse en su simulacro, es de hecho el monstruo anunciado por las Parcas; luego la fragua en que los Cíclopes forjan las armas de los héroes, y, por fin, la lúgubre gruta de las Parcas en el fondo del «teatro de bosque». Es precisamente este antro, colocado en el último punto de fuga de una perspectiva en abismo, que aclara el valor simbólico más profundo del topos-caverna: obscura cavidad, inalcanzable por la mirada, aunque su boca se abra, en el fondo del escenario, gracias a artificios mecánicos, evocando la imagen de un monstruo infernal. Pero, al mismo tiempo, puede ser vientre materno, entrañas de la Madre-Tierra sede de los antiguos ritos iniciáticos y de regeneración, absoluta coincidencia entre la vida y la muerte según una concepción órfico-platonizante, y, en esta ocasión, como morada de las Parcas, ineluctable destino de muerte.

Gracias a este simbolismo profundo y polivalente, la torre de la bella Escila en El golfo de las sirenas es un lugar de donde los hombres precipitan por efecto de las artes mágicas de la sirena, quedando enredados en las riendas del Eros; pero también el lugar de donde se puede precipitar hacia un mortal abismo, como en La púrpura de la 
rosa. Y aquí es una gruta puesta al pie de una montaña. Marte, solicitado a entrar, responde: «... Aunque fuera / al báratro, entrara en él». $\mathrm{Y}$ es de veras el lugar más horroroso:

MARTE ... nunca la planta, pues, nunca la vista,
pisó temerosa, previno confusa
tan lóbrega estancia, mansión tan horrible,
prisión tan funesta ni cárcel tan dura.
A la escasa luz que dispensa
el torpe bostezo que entreabre la gruta
porque el sol que de miedo no pasa
de lejos la acecha aún más que la alumbra,
melancólico espacio diviso
de negras paredes, que teas ahúman,
colgadas de grillos, cadenas y lazos,
trofeos que infaman deidad que no ilustran.

En este caso la gruta se construye a través de una condensación de todos los significados que connotan el motivo de la cueva. Y en este abismo, donde vive prisionero el Desengaño, Marte llegará a descubrir los amores de su esposa Venus con el bello Adonis. Otra vez, pues, el Eros anuncia de forma ineluctable el Thánatos. Así en Apolo y Climene, los dos amantes celebrarán sus bodas nada menos que en la gruta encantada de un mago. Pero luego acaece que Apolo, perdonado por los dioses, se ve obligado a abandonar allí en la gruta a su esposa para volver a ascender otra vez al Olimpo.

Otro momento de entropía simbólica se alcanza en El monstruo de los jardines, por el hecho de que tanto la caverna montana donde vive Aquiles como el palacio real de su amada Deidamia, donde el héroe se esconde disfrazado de mujer, desarrollan al mismo tiempo la función de prisión, antro encantado, fragua en donde se forja el «monstruo» - es decir, la metamorfosis del protagonista—, y por fin de lugar símbolo de las profundidades del abismo, infierno del alma. De hecho, Aquiles aquí se enfrenta con su tiránica madre, o sea con el doble malogrado de su misma representación, como demuestra su disfraz. Sin embargo, el protagonista llegará a la agnición final, gracias al amor de Deidamia, por fin sustitutivo del de la madre. 
Los tres siguientes mitologemas, que hemos definido: «el monstruo», «el nacimiento», «el simulacro», se presentan la mayor parte de las veces anudados por relaciones de constelación generando complejos motivos que constituyen su interconexión.

El mitologema del «monstruo», del portento, al que en general introduce el mitologema el "lugar iniciático», se articula, a su vez, en base a cuatro motivos: "el monstruo de hermosura», belleza desconcertante y fatal; «la fiera» o el hombre-fiera», o sea el salvaje (pero a veces los dos motivos pueden coexistir de forma dialéctica); «el prodigio o portento» en todas sus formas, ya sea una escena reveladora o una intervención divina, o un objeto de veneración y/o mágico; «la bestia sapiente", animal u hombre con funciones nodrizas y de pedagogo, como en todo ritual iniciático. La simbolización general de los cuatro motivos concierne a la problemática del Sujeto y de su «estar» en el mundo.

El sucesivo mitologema del «nacimiento» parece plantear la clásica cuestión de Lévi-Strauss ${ }^{8}$ : ¿nacemos de uno solo o de dos?, y por tanto atañe a la figura paterna o materna, a la coerción tiránica o la ausencia trágica de uno de los dos, capaces incluso de reemplazarse uno a otro según el caso, causando desequilibrios y caos en el hijo. En el plano de los «motivos» podemos resaltar: los mecanismos de agnición, ya en escena desde la antigüedad; el Padre-tirano (a veces la Madre) carcelero y devorador mítico de sus propios hijos, o al menos de su existencia y de su alma; el fantasma paterno (a veces materno) que aletea inderogable y que traza el destino heroico y/o trágico del hijo; la Ausencia de ese mismo fantasma y por tanto del nomos y del nombre, que conlleva el manque-à-être del héroe. De eso podemos deducir cuánto la selección calderoniana se acerque a las liturgias rituales y tribales, y por consiguiente, cuánto sea fundante la ligazón entre culturas tribales y civilización barroca, como subrayó Barthes ${ }^{9}$. Naturalmente en este caso el mitologema tiene que ver con la Ley, con la identidad o falta de identidad del héroe.

Asumimos como ejemplo fundante del mitologema del «nacimiento", por su valor paradigmático, La vida es sueño. El punto de acmé de la lucha entre padre, opresor de la existencia y alma de su propio hijo,

8 Lévi-Strauss, 1966.

9 Barthes, 1972, pp. 141-248. 
se manifiesta en aquel grito de dolor que Segismundo lanza contra el rey su padre Basilio llamándolo «Tirano de mi albedrío» (II, vv. 14401531).Y así Liríope, tiránica madre de Narciso, en vano intentará cambiar el rumbo de su destino, declarado por los Cielos:

LiRíope Todos los medios que puse para estorbar los empeños hoy de su destino, han sido facilitarlos más presto; pues la voz de Eco le aflige, y por venir de ella huyendo, muerte le da su hermosura: con que ya cumplido veo que hermosura y voz le matan amando y aborreciendo.

El mitologema del «simulacro» se manifiesta con una manufactura magistral y/o prodigiosa, digna así de toda veneración y, gracias a ella, a través de una metamorfosis, se transforma en elemento humano o divino; como un auténtico tótem, centro de la veneración cultural y «axis mundi»; y por último, como representación del muerto, icono congelado, vivo-cadáver, elemento conmutador de la vida por la muerte y viceversa. Sintetiza simbólicamente este mitologema la transformación de Anajarte en estatua en La fiera, el rayo y la piedra. La lengua poética calderoniana llega a su máximo nivel de expresión en la representación de Anajarte transformándose en estatua. La función proxémica del aparte, se hace metáfora de un espacio virtual: la voz interior de Anajarte - como subraya la presencia del paréntesis- que está sufriendo la metamorfosis de bello cuerpo animado a cuerpo congelado en el frío mármol:

A partire da questo simulacro che si erge come Significante assoluto al centro della scena, è possibile intraprendere la salita ai cieli, cioè il cammino della conoscenza che si esercita sui diversi gradini dell'Eros, così come vuole l'elaborazione platonizzante di provenienza italiana e rinascimentale $^{10}$.

10 Cancelliere, 1984, p. 300. 
La simbolización de todo el mitologema remite al «Doble», la imaginación especular, es decir, al viaje del héroe entre Eros y Thánatos.

El estanque artificial en que se representa El mayor encanto, Amor, es verdaderamente una "piscina» de los tres mitologemas antedichos y de sus varios motivos.

El salvaje Arsida esclavo de las pasión por voluntad de la maga Circe representaría la naturaleza salvaje e indómita, y el caos del alma supeditada por el poder de la hechicera Circe. En la isla las transformaciones mágicas van repitiéndose continuamente; algunas se inspiran en los lazos de la Commedia dell'Arte, como, por ejemplo, la del gracioso Clarín, sumamente divertida, transformado en mona; otras, en cambio, de eco homérico, ovidiano, etc. Recordemos las transformaciones de los compañeros de Ulises en brutos y las de los dos amantes infelices, Lisida y Florida, en árboles. El motivo metamórfico, de hecho, domina todo el plot no solo como connotación del poder mágico de Circe y de la atmósfera encantadora de la isla, sino también de la naturaleza, de los personajes, y, por fin, de todo lo que acaece en ese lugar.

Ese caos de la vista y del entendimiento humano terminan con la aparición al héroe Ulises de la sombra de Aquiles: verdadero fantasma que puede asignar el destino al hombre, destino que coincide con el «deber ser» que le es propio. Desde este punto de vista la sombra de Aquiles desarrolla la función del fantasma paterno que en los ritos aparece en el fondo del lugar iniciático. A partir de ese momento el héroe se libera del extravío de la mente causado por las pasiones, y recobrada la razón, puede ahora cumplir con el destino asignado a su existencia. Por otra parte, precisamente el tiempo dramático del deus ex machina muchas veces se relaciona con una revelación de paternidad, real o divina (el Padre entendido como Primero antepasado de la comunidad).

El monstruoso Centauro Neso, habitante de las selvas, rapta a la bella Deyanira en Los tres mayores prodigios. El sacrificio que Hércules ofrece a Júpiter en el templo del monte Oeta en acción de gracias por haber salvado a su esposa, es el preaviso de las llamas que abrasarán el cuerpo del héroe en presencia de todos los actantes:

HérCules Siento un ardor, que me aflige y que me abrasa. Todas mis voces son rayos, 
todos mis alientos llamas, fuego vierto por los ojos.

(p. 1588)

Sin embargo gracias a este sacrificio el héroe, que desde el principio se había mostrado como una fiera y, al mismo tiempo como un monstruo o prodigio, ahora volverá a unirse con el Padre, como apoteosis de gloria divina.

En La fiera, el rayo y la piedra las proféticas Parcas anuncian la llegada de un monstruo que será el niño dios Cupido. Instrumento de la venganza de Amor será la fiera y cruel Anajarte que, a comienzo de la obra, aparece en un "teatro de bosque». Su total rechazo de la pasión amorosa causará su transformación en estatua que va a sustituir la que campea en una fuente al centro de un teatro de jardín. En cambio esta, gracias al amor de Pigmalión, cobrará vida. Caos de las pasiones no correspondidas, metamorfosis, simulacralidad, son los signos de la lucha sin cuartel entre los dos hijos de Venus, Eros y Anteros, atormentando a los hombres, y que, de hecho, corresponden a las dos «naturalezas» de la diosa: la Venus Urania y la Venus Pandemia.

Pero, ¿por qué la única víctima acaba siendo la desdeñosa Anajarte? De hecho, la reina de Trinacria por su naturaleza fría y altanera, desde el comienzo se presenta como estatua humana. Su incapacidad de amar fue decretada desde su nacimiento, cuando fue puesta en la cuna en lugar de la verdadera hija del rey de Trinacria, Irífile. Desde entonces vive su existencia en función, aunque inconsciente, de la búsqueda de su identidad y de su verdadero padre. Pattern simbólico, el personaje de Rosaura en La vida es sueño. No por casualidad, pues, a lo largo de una fuga inserta en un abismo de la escenografia, el simulacro está colocado en el centro del teatro, eje vertical de la fuente, en fin como axis mundi. De hecho, esta deixis del espacio construye los significados profundos de la fábula: la estatua se hace criatura humana: la bella Irífile consigue un doble triunfo, recobrando el trono que le habían usurpado y celebrando su amor con Céfiro; mientras la cruel Anajarte está condenada para siempre: cumpliose su destino trágico. El hecho de que la acción se desarrolle en un «teatro de jardín», lugar-símbolo del triunfo de la razón, obedece a la prodigiosa capacidad dialéctica del poeta. 
En Fortunas de Andrómeda y Perseo la búsqueda de identidad del atormentado héroe se concluye con un éxito feliz. El tema ya había inspirado a Lope de Vega La fábula de la bella Andrómeda y Perseo (1621) y otras representaciones en música como la Andromède de Corneille (1650). En la obra calderoniana todos los acontecimientos: la decapitación del monstruo caótico, Medusa, la lluvia de oro en que se transforma Júpiter, el sueño revelador, el asesinato del monstruo marino que estaba para devorar a Andrómeda, etc., son las etapas heroicas de una temeraria búsqueda del Padre ausente que el héroe intentará a través de esas empresas; búsqueda que acabará con la apoteosis final cuando Júpiter, al aparecer en el «teatro de cielo», confirmará a Perseo su paternidad.

El mito, de origen oriental, del bello Adonis destrozado por un jabalí animado por Marte, correspondería, respectivamente, al símbolo de la primavera y al del invierno. Sin embargo Calderón, en La púrpura de la rosa, sigue la tradición a partir de la helenístico-humanística hasta Shakespeare, Marino, y la ofrecida por las artes figurativas (como muestra la pintura de Tiziano) según la cual en este mito es fundante el tema del «doble» entre el monstruo y el dios; el jabalí y el celoso Marte. Por otra parte, la imagen destrozada de Adonis es el doble especular de su falta de identidad que radica ya desde su nacimiento, como afirma el bello pastor:

ADONIS Quien aborrecido hijo tan [desgraciado] nació de sus padres, que aun en ellos no supo que era afición. [...]

Nací bastardo embrión, maldecido de mis padres, y con tan grande maldición como que de un amor muera.

El mitologema del «monstruo» se relaciona con el motivo del Infierno en Celos, aun del aire matan, aquí simbolizado por las Furias que había suscitado Diana airada.

En Apolo y Climene el mismo mitologema se presenta a través del motivo del elemento prodigioso como síntesis del Padre y de Apolo. 
Está presente también el coadyuvante con función de «bestia sapiente», aquí el mago Fitón que vive en el fondo de su caverna alquímica.

En Ni Amor se libra de Amor Siquis vive en un suntuoso palacio encantado protegida por su amado - el dios Cupido al cual, nunca ha visto- para protegerla de las iras de su madre Venus. La joven imagina pues que su amante será un monstruo horrendo; a aquel «monstruo de hermosura", pues, hijo e imagen especular de una madre tiránica sustitutiva de la imagen paterna, en su imaginación lo ve como una fiera anormal, la confusión hecha semblante. Sin embargo, cuando, durante un encuentro nocturno, la luz deja ver en toda su belleza al joven, Siquis, turbada, exclama:

SiQUis

¿Quién vio más bella pintura?

¿Quién más perfecta escultura?

El que dijo que este es

un monstruo, dijo bien, pues

es un monstruo de hermosura.

(p. 1979)

Luego Siquis debe sufrir varias peripecias consecuencia de las persecuciones de la tiránica Venus, pero llegará a salvarse gracias a la función coadyuvante de distintas «bestias sapientes». "Bestias sapientes» negativas son, en cambio, las hermanas envidiosas, que, llegadas al palacio, intentan convencerla de haberse unido con un monstruo.

En El monstruo de los jardines puede notarse una concentración de los mitologemas del «monstruo», del «nacimiento» y del «simulacro». Tetis es una madre tiránica - como Liríope con respecto a Narciso y Venus a Cupido - para con el joven héroe Aquiles, al cual obliga a vivir como un salvaje en una gruta entre los montes con el fin de protegerlo de los peligros. Cuando lo esconde en el Palacio de Licomede para que pueda escapar de la guerra de Troya que está para estallar, recurre a una estratagema ayudándolo a disfrazarse de mujer, y lo hace con tanto esmero y ornando su bello semblante con tantos adornos que la fiera humana acaba por adquirir una fisonomía femenina, «monstruo de hermosura» que, con menor eficacia, Tirso había dibujado en su Aquiles (1636). Es Tetis, pues, quien llamando a voces a todas las ninfas del mar, les ordena transformar un monstruo en otro gracias a los más maravillosos adornos: 
Tetis

\author{
Que con los más suntüosos \\ adornos, joyas y telas \\ que en los archivos del mar \\ la hidrópica sed encierra, \\ a aqueste bruto diamante \\ pulir tratéis, de manera \\ que el que fue asombro de horror, \\ pase a serlo de belleza, \\ cuando mujeriles pompas \\ tanto su forma desmientan \\ que sea monstruo en los jardines \\ el que fue monstruo en las selvas.
}

(p. 2000)

Sin embargo, gracias al amor de Deidamia, Aquiles llegará a recobrar su orgullo recuperando su imagen viril y empuñando las armas, desdeñoso de la muerte anunciada por el oráculo; una imagen que ahora evoca el totémico simulacro paterno. Su fuerte valor icónico no puede dejar de evocarnos los tapices de Rubens relativos al ciclo de las Historias de Aquiles del Museo Diocesano de Ancona.

En Fieras afemina amor los monstruos, fieras, tiranos contra los cuales lucha Hércules, son la representación, según la tradición humanística, de los vicios y los males contra los cuales se enfrenta el héroe, cuyo ánimo fuerte, lo hace emblema del coraje y de la virtus. Sin embargo, Hércules al mismo tiempo está representado según el icono de la fiera humana vestido de la piel de un león y armado de maza, emblema comprobado, desde Séneca hasta Marsilio Ficino, de la Fortitudo y de la sabiduría que de esta deriva. En esta pieza Calderón presenta a Hércules insensible al amor. Por venganza de Venus y su hijo, el héroe sufrirá de una pasión amorosa por la infanta de Libia, Yole. Después de varias peripecias será esta quien se vengue de Hércules ordenando a sus damas adornarlo, mientras está dormido, con galas de mujer. El disfraz femenino construye ahora un monstruo de la naturaleza, asombro para todos que se opone dialécticamente al monstruo, la fiera humana, por su fortitudo.

En Fineza contra fineza el plot se desarrolla en torno a un eje que es el simulacro de Venus en el templo de Tesalia, donde antes se veneraba a Diana, y que ahora, gracias a la sustitución del simulacro, está dedicado al culto de la diosa del amor. De hecho es la estatua el ac- 
tante que, en base a su presencia en el templo, o a su ausencia, puesto que en cierto momento desaparece, suscita desdichas de amor y felices epílogos.

La estatua de Prometeo es el simulacro de Pandora, hecho por Prometeo-Pigmalión, que ya a su aparecer se hace objeto de veneración por su prodigiosa belleza. Forjada a semejanza de la diosa Minerva, la estatua empieza a animarse y hacerse humana. A partir de ahora este simulacro vivo actúa como protagonista causando varios lances de guerra y de amor, metaforizando, en fin, la dialéctica entre Caos y Cosmos.

En otra ocasión he analizado el tema icónico de esta "fiesta real» a partir de las versiones originarias del mito que llegan a las teorías neoplatónicas sobre el valor trascendente de la imagen y luego a las de los Padres de la Iglesia y del Concilio de Nicea, hasta el neoplatonismo renacentista. Y es el mitologema del simulacro el que construye la acción a través de una red de relaciones especulares que la «fiesta» de forma sorprendente pone en escena: la doble naturaleza de Pandora entre materia y modelo hiperuranio (espíritu); el doble Pandora-Minerva, Minerva-Pálade, Prometeo-Epimeteo, etc. La "fiesta», en fin, a través de su aparato escenográfico, dramático y musical, llega a celebrar el poder de civilización de las Artes y la primacía del conocimiento y sabiduría para la humanidad:

Se ha realizado así, bajo la égida de Apolo, la unión entre la mente humana sabia, creativa y valiente y el viviente simulacro que representa las bellas formas intelectivas de todas las Artes y de todas las Ciencias, el paso de las obras terrenas a la forma sublime que la trasciende ${ }^{11}$.

Sexto, el mitologema del «Eco»—procedimiento estético-filosófico difundido en la música barroca a partir de la Camerata en adelante- acoge el "poder de la música» como encantamiento o como lenguaje, fuente de extraordinarias empatías, según la concepción neoplatónica de la época (recordemos, entre los muchos ejemplos, El mercader de Venecia de Shakespeare). La música, además, articula la deixis del espacio y del tiempo. En particular uno y otro se miden, se refractan y reflejan y en fin se hacen metafísicos y cósmicos, gracias a

11 Cancelliere, 2010, p. 84. 
la «música en eco», manifestación propia de la fuerza del Eros humano y cósmico. Esta articulación espacio-temporal se hace visible al acoger en el mitologema, según un proceso de sustitución metafórica, la aberración de perspectiva o laberíntica de la escenografia, pero también el caos laberíntico que construye al personaje a través de las vicisitudes de la vida y de su ánimo hasta empujarlo a la locura, a la esquisis, a la perversión de su imagen al espejo, etc. En definitiva, el mitologema del «Eco» da cuenta de un cosmos-espejo correspondiente a la relación del Yo con la subjetividad que lo representa, y por tanto significa el lenguaje y al mismo tiempo la des-estructuración del lenguaje, la afasia, el horror vacui, el olvido.

La difusión del mitologema del «Eco» corre paralelamente a la práctica de la música en todo el corpus de las comedias palaciegas, de las zarzuelas, pero también de verdaderas "óperas» según el estilo de la Camerata dei Bardi, como La púrpura de la rosa o Celos, aun del aire matan —que Calderón llamaba representación-música- donde recitativos con acompañamiento, que preparan el canto desplegado de las «arias», sustituyen a los monólogos y diálogos no musicados. La poesía de Calderón, por otra parte, no sólo sostiene la musicalidad, sino también reproduce, en la dialéctica entre personajes y coros, su desarrollo «en eco» proponiendo estribillos que insistentemente se repiten perdiéndose a veces en la repetición de fragmentos de los últimos versos hasta la de las últimas sílabas. Podemos presumir, pues, que la música hacía lo mismo ampliando en su correspondencia especular ad infinitum con la palabra, el espacio encantado, melancólico, ahora pleno de infinitas resonancias errantes, animadas por un deseo que anhela a su objeto.

Vamos a analizar el «mitologema del eco» a partir de un ejemplo que consideramos paradigmático y fundante del propio mitologema. En la jornada III de la representación-música, Eco y Narciso, Liríope, preocupada, a causa del horóscopo, por su hijo Narciso enamorado de Eco, prepara para la pastora una poción venenosa que la obliga a repetir las últimas palabras pronunciadas por voces ajenas, y le provoca una afasia que le impide articular en discurso el propio pensamiento. Eco se hace, pues, la personificación misma de un cosmos atravesado por refracciones sonoras, manifestación de un Eros cósmico que en la repetición de los sonidos hace propias las trayectorias, distintas y contrarias al mismo tiempo, del deseo: 
NARCISO ¡Confusión rara!

Eco...

ECO

Eco.

NARCISO

Qué es esto?

ECO

Esto.

$$
\text { [...] }
$$

Narciso Qué es lo que quieres?

ECO

Qué quieres?

NARCISO

Tú me detienes y llamas.

Dímelo tú a mí.

ECO

Tú a mí.

NARCISO

Suelta.

ECO

NARCISO

Suelta.

ECO

Basta.

Basta.

(p. 1934)

Así, en una época en la que el canto y la música barrocas «en eco» se afirman, en esta comedia calderoniana se asiste a los efectos sorprendentes de la música que se despliega en un "aria» para expresar el monólogo interior, como el de Eco en un aparte:

Eco (Por de dentro, hacia mí misma, sin articular palabra hablar puedo, pues conozco que pronunciar bien le falta al órgano de mi voz, aunque no sé por qué causa).

La lamentación de la muchacha tan cruelmente dividida entre cuerpo y voz en su icono mítico es la consecuencia del crimen de Liríope:

LiRíope De Eco la voz y hermosura sus dos peligros se ven: pues destruyamos el uno, 
para que quede después

el otro imperfecto.

(p. 1930)

De acuerdo con la crítica analítica, nos recuerda Barthes ${ }^{12}$ que la voz es una caída de la imagen fuera del cuadro, una trayectoria del deseo del sujeto hacia el objeto desconocido que escinde la imagen especular entregándola a la errancia.

Calderón no hace sino asumir el mito en todas sus valencias para alcanzar ese resultado asombroso de complejidad escénica, donde la voz «en eco» de la protagonista puede alternar con el canto desplegado de su interioridad, y ambos hacen sonoro el Cosmos, atravesado contemporáneamente por la voz plena, pero no audible de Eco, y por sus manifiestas, si bien incompletas, refracciones: a causa de eso, el pobre Narciso, por antonomasia icono de su misma imagen, no puede más que morir a pesar de los cuidados maternos, así como mueren las flores desvaneciéndose en un día de gloria.

En algunos casos, como en la égloga piscatoria El golfo de las sirenas, la música es el tema mismo de la pièce. La voz suave de la hechicera Caribdis o el canto fascinante e irresistible de las sirenas se esparcen en las refracciones cósmicas de un eco que va diluyendo ese canto en los versos repetidos y cortados que se alternan entre personajes y coros: neoplatónicamente el cosmos-espejo es un cosmos musical que nos ilusiona y nos entrega al olvido.

Aquí el eco se repercute de un teatro de selva donde se encuentra Caribdis a un teatro de mar, detrás del escenario, de donde responden las Sirenas:

$\begin{array}{ll}\text { CARibdis } & {[\ldots]} \\ & \text { ¡Hola, aho! Ah del golfo Cant } \\ & \text { de las Sirenas! } \\ & \text { Dentro cantan. } \\ \text { Sirenas } & \text { ¡Hola, aho! Quién nos llama } \\ & \text { desde la selva? } \\ \text { CARIBDis } & \text { Ya la voz de Caribdis } \\ & \text { no hay quien conozca? }\end{array}$

12 Barthes, 1972, pp. 90-91. 
[...]

DOS SIRENAS

OTRAS DOS

CARIBDis

UNA SIRENA

OTRA

OTRA

OTRA
[Dentro] Pues que mandas?

$$
\text { Qué quieres? }
$$

Que en calma sienta, llore, gima y pene...

[Dentro] ... Sienta...

... llore...

... gima...

... pene...

(p. 1735)

En El laurel de Apolo la desesperada peroración del dios con el fin de que Dafne resolviera amarlo se articulaba en parte a través de un recitativo y en parte a través de un «aria». Pero también la víctima infeliz cantaba su súplica invocando piedad al violento dios y al padre ausente, el río Peneo, poniendo como testigo la naturaleza a través de sus cuatro elementos.

Y siempre la música alivia las melancolías de Siquis, prisionera del desconocido y amado Cupido en Ni Amor se libra de Amor, según una función terapéutica propia de la música, ya a partir de Teofrasto y Asceplíades:

Así, una de las más antiguas concepciones de la humanidad, manifestadas no solo en las enseñanzas de los pitagóricos, sino también en los mitos de Orfeo y en la historia bíblica de Saúl y David, fue asociada a la teoría platónica de los efectos morales de las distintas claves musicales para formar una «terapia musical ${ }^{13}$.

En La estatua de Prometeo la estructura musical «en eco» es congenial con el tema neoplatónico del doble que hermenéuticamente desvela el significado profundo de la "fiesta». Así, entre arias y recitativos, se reiteran los estribillos calderonianos que escanden la progresión completamente especular del plot y de las escenografias en abismo. «La tierra con flores, el agua con perlas / el aire con plumas, con salvas el eco»: este es el estribillo repetido que invita con evocaciones cosmogónicas a recibir los dones guardados en la urna de Pandora-

13 Klibansky, Panofsky, Saxl, 1983, p. 43. 
Minerva. Pero si Apolo entona melancólico "Que nazca para morir...», al dios responde varias veces la Música misma con «Tú mueres para nacer...», concluyendo con la fórmula coral expresada con toda su ambivalente complejidad: "Ahí de quien vio / el bien convertido en mal, / y el mal en peor», a la cual sigue dialécticamente: «Felice quien vio / el mal convertido en bien / y el bien en mejor» ${ }^{14}$.

Carácter repetitivo de la música y duplicidad de la escena, del teatro, de los destinos humanos, de la historia, hacen del viaje de la existencia humana en este mundo un itinerario que solamente la fe en la utopía puede salvar, la aspiración a aquel modelo inimitable que reside en el Hiperuranio, que quizá un día vuelva a la tierra con el retorno de Urano. Se encierra en ello la entropía simbólica del desengaño de autor y de toda una época.

Séptimo, el mitologema del «Sueño» se articula entre la profecía (horóscopo, vaticinio, etc.) que traza el destino del héroe; el sueño entendido onírica y físicamente, desmayo, pérdida de consciencia; y la visión reveladora o simbólica que puede seguir a este estado (pero que puede generarse también en otros momentos). Los tres motivos conducen al cuarto: el del descubrimiento de la ilusión, del vano ensoñarse del sujeto y del mundo entero, o sea de la asunción del sentimiento agudo del desengaño. El mitologema aúna el sentimiento del ineludible destino, de la vanitas vanitatum, pero también de la quimera, y por esta vía la opuesta y utópica visión de la «basilización» o de la aproximación de una renovada Edad de Oro. Otra vez ejemplo paradigmático es La vida es sueño.

Un horóscopo decide el cruel destino de Narciso: una voz y una belleza, las cualidades escindidas del fantasma de Eco, causarán su fin, en la red de la contraposición dialéctica amor-odio.

Un oráculo en el templo de Venus anuncia que la bellísima Siquis será esposa y presa de un monstruo, desencadenando el deseo de la diosa envidiosa para que esto suceda realmente. Una predicción de vida guerrera breve, pero gloriosa, obliga a Aquiles al disfraz impuesto por Tetis, etc.

Manifestaciones de técnica de la apoteosis final — cantada, musicada, bailada - enmarcada en una escenografia de gran espectacularidad, son el triunfo del Amor correspondido como colofón de La fiera,

${ }^{14}$ Ver Cancelliere, 2010, pp. 70-71, 77-78. 
el rayo y la piedra; Júpiter en el trono solar confirmando su paternidad a Perseo; Venus y Adonis elevados a constelaciones en la gloria inmortal de su amor; Cupido que al aparecer como Deus ex machina proclama el triunfo del Amor al término de las intrigas engañosas de Fineza contra fineza; las bodas de Prometeo y Pandora celebradas por el mismo Apolo, en la explosión final de la «fiesta» en toda su ilusoria espectacularidad.

De todas formas no sabemos lo que cuenta en estos triunfos y apoteosis la dimensión del sueño, de las visiones ilusorias y de la esperanza, y cuánto de todo esto sirve para hacernos constatar, en el deslumbramiento de la vista y de los sentidos, la dimensión de la ilusión, de la cual el teatro representa el único signo tangible y posible. Sin embargo, a estas visionarias apoteosis preceden a menudo sueños enviados al héroe por misteriosas Alteridades, paternas o divinas. Pues, Perseo sueña su triunfo al lado de su padre, y Adón está obsesionado por un sueño que le recuerda su incierta paternidad y, a la vez, le hace prefigurar su futuro desgraciado y horroroso fin.

En conclusión, Calderón usa la fábula como patrón emblemático que permite investigar el tema universal de la Subjetividad, ya que este Sujeto, desplazado de su centro, se representa a partir de una insuperable distancia entre él y lo Real. Se configura, pues, el nuevo héroe moderno entregado a una inmóvil soledad o a una errancia donde el recorrido iniciático no se concluye con el conocimiento de lo verdadero, sino con la resignada consciencia de la finitud humana y existencial.

Y así Segismundo, al que siguen Perseo, Faetón, Climene, Céfalo, Narciso, Aquiles, Adón, Prometeo, Siquis, Eco, Caribdis, y tantos otros héroes del mito no serían más que sombras fantásticas, las existencias que se proyectan emblemáticas sobre la condición humana existencialmente vivida e interpretada por el autor mismo.

De aquí derivan las variaciones e interpretaciones personales de los mitos calderonianos prescindiendo de las sólidas tradiciones clásicas y humanístico-renacentistas que el mismo autor acoge: el origen, por tanto, de esos topoi mitológicos insistentes y que se repiten, que aquí hemos llamado «mitologemas».

Enfoque hermenéutico que reconoce en el desengaño - metáfora supeditada a la entera «fábula» mitológica calderoniana- el desengaño de Autor, del Sujeto y de toda una época dolorosamente inda- 
gada. El desengaño de una época que sustituye los valores imperiales con sus vanas pompas, la representación, y que emblemáticamente asume el teatro como lugar reservado para una espléndida muestra de las vanidades por el poeta, estoicamente, reconocidas como tales. Y a pesar de todo ensalzadas, gracias a una utopía siempre posible y soñada, a una palingenesia - mítica y arcádica - a las cuales se entregan, a través de la representación, el mismo poeta, el Sujeto, la profunda crisis epocal que los define y determina en el proceso oscuro de la historia. 


\section{BibliografíA}

Barthes, R., Saggi critici, Torino, Einaudi, 1972.

Calderón de la Barca, P., Obras Completas. Dramas, ed. Á.Valbuena Briones, Madrid, Aguilar, 1966.

- La fiera, el rayo y la piedra, ed. A. Egido, Madrid, Cátedra, 1989.

Cancelliere, E., "La torre e la spada. Per un'analisi de La vida es sueño», Quaderno di Lingue e Letterature Straniere, 8, Università di Palermo, 1979, pp. 41-110; y en "Appendice», P. Calderón de la Barca, La vita è sogno, trad. (a cura di) E. Cancelliere, Palermo, Novecento Edizioni, 2000, pp. 273-331.

- "Campo dello sguardo e della parola in una commedia di Calderón», en Semiotica della rappresentazione, a cura di R. Tomasino, Palermo, Flaccovio Ed., 1984, pp. 295-303.

— «Pandora: mito e icono para una fiesta real», Anuario Calderoniano, 3, 2010, pp. 67-86.

Chapman, W. G., «Las comedias mitológicas de Calderón», Revista de Literatura, 5, 1954, pp. 35-67.

Egido, A., Introducción a la ed. de Pedro Calderón de la Barca, La fiera, el rayo y la piedra, Madrid, Cátedra, 1989.

Frazer, J., Il ramo d'oro, Torino, Einaudi, 1973.

Freud, S., Totem e tabù, Torino, Boringhieri, 1989.

Greimas, A. J., Semantica strutturale, Milano, Rizzoli, 1969.

- Sul senso, Milano Bompiani, 1974.

Klibansky, R., E. PANOFSky y F. SAXL, Saturno e la melanconia. Studi di storia della filosofia naturale, religione e arte, Torino, Einaudi, 1983.

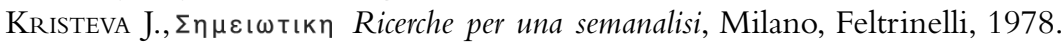
LÉvi-Strauss, C., Antropologia strutturale, Milano, Il Saggiatore, 1966.

Propp, V. J., Morfologia della fiaba, Milano, Sugarco Edizioni, 1990. 